Review

\title{
In Vivo Applications of Single Chain Fv (Variable Domain) (scFv) Fragments
}

\author{
Philippe P. Monnier ${ }^{1,2,3, *}$, Robin J. Vigouroux ${ }^{1,2}$ and Nardos G. Tassew ${ }^{1,2, *}$ \\ 1 Genetics and Development Division, Toronto Western Research Institute, MCL-6-415, 399 \\ Bathurst Street, Toronto M5T 2S8, Ontario, Canada \\ 2 Department of Physiology, Faculty of Medicine, University of Toronto, Toronto M5S 1A8, \\ Ontario, Canada \\ 3 Department of Ophthalmology, Faculty of Medicine, University of Toronto, Toronto M5S 1A8, \\ Ontario, Canada
}

* Authors to whom correspondence should be addressed;

E-Mails: pmonnier@uhnres.utoronto.ca (P.P.M.); ntassew@uhnres.utoronto.ca (N.G.T.);

Tel.: +1-416-603-5295 (P.P.M.); Fax: +1-416-603-5126 (P.P.M and N.G.T.).

Received: 4 February 2013; in revised form: 25 March 2013 / Accepted: 29 March 2013 /

Published: 11 April 2013

\begin{abstract}
Single chain variable domain $(\mathrm{Fv})$ fragments $(\mathrm{scFv})$ are powerful tools in research and clinical settings, owing to better pharmacokinetic properties compared to the parent monoclonal antibodies and the relative ease of producing them in large quantities, at low cost. Though they offer several advantages, they suffer from lower binding affinity and rapid clearance from circulation, which limits their therapeutic potential. However, these fragments can be genetically modified to enhance desirable properties, such as multivalency, high target retention and slower blood clearance, and as such, a variety of $\mathrm{scFv}$ formats have been generated. ScFvs can be administered by systemic injection for diagnostic and therapeutic purposes. They can be expressed in vivo through viral vectors in instances where large infection rates and sustenance of high levels of the antibody is required. ScFvs have found applications as tools for in vivo loss-of-function studies and inactivation of specific protein domains, diagnostic imaging, tumor therapy and treatment for neurodegenerative and infectious diseases. This review will focus on their in vivo applications.
\end{abstract}

Keywords: scFv; recombinant antibodies; in vivo expression; adeno-associated virus (AAV); immunotherapy 


\section{Introduction}

Antibodies are the body's defense system to neutralize bacteria and viruses. They recognize and bind a target molecule through the antigen binding sites located on the two Fab segments, which are specific to a particular epitope on an antigen. The fragment crystallizable (Fc) domain binds to $\mathrm{Fc}$ receptors and recruits cytotoxic effector molecules and, by interacting with the neonatal Fc receptor, provides long serum half-lives [1,2]. Full length monoclonal antibodies (mAbs) have found various uses as tools in a number of therapeutic applications $[3,4]$. However, there are situations in which the Fc-mediated effect is undesirable. For instance, unwanted activation of Fc receptor-expressing cells may lead to toxicity through cytokine release [5]. The long serum half-life could also be undesirable in imaging applications, where faster clearance is required in order to limit exposure to radionucleotide molecules [5]. Thus, mAbs have been manipulated to improve their therapeutic potential. Initially, the Fc domain has been removed through proteolysis with enzymes, such as papain and pepsin [6], to yield $\mathrm{Fab}$ fragments. Later, advances in antibody engineering have enabled the further reduction of mAbs to single chain Fv fragments (scFvs), monovalent Fabs, diabodies and minibodies [7-10]. The properties of these fragments have been tailored to optimize their binding affinity, in vivo pharmacokinetics, stability and expression levels [11]. ScFvs have provided an alternative to full-length mAbs in diagnostic and therapeutic applications and account for $35 \%$ of antibody fragments in clinical trials $[5,12,13]$.

An scFv fragment consists of the smallest functional antigen-binding domain of an antibody ( $\sim 30 \mathrm{kDa})$, in which the variable heavy $\left(\mathrm{V}_{\mathrm{H}}\right)$ and variable light $\left(\mathrm{V}_{\mathrm{L}}\right)$ chains are joined together by a flexible peptide linker [14] (Figure 1). The first scFv fragments were cloned by two labs in the same year, Bird et al. [15] and Huston et al. [16] in 1988. The length and amino acid composition of the linker are crucial in maintaining the correct folding of these proteins [17]. The linker is typically about $3.5 \mathrm{~nm}$ in length and must contain hydrophilic residues together with stretches of Gly and Ser sequences for flexibility, in addition to Glu and Lys for enhanced solubility [18,19]. ScFv fragments are most often produced in bacterial cells [20], although other expression systems, including mammalian cells [21], plants [22] and insect cells [23] have been employed.

$\mathrm{ScFv}$ fragments retain the binding specificity of the parent antibody and offer several advantages compared to full-length mAbs. They display improved pharmacokinetic properties, such as better tissue penetration and rapid blood clearance, which may be beneficial in radiotherapy and diagnostic applications. For instance, these fragments can penetrate more rapidly into tumors compared to an intact antibody [24,25]. Also, when scFvs are joined to radionuclides in radiotherapy applications, their increased rate of clearance from blood minimizes exposure to healthy tissue [26,27]. Recombinant antibodies lack the Fc region, leading to low immunogenicity, making them better therapeutic agents compared to the full-length mAbs for many applications. In addition, scFvs can be cloned and expressed in bacterial and mammalian cells, making it possible to produce large quantities easily and cost-effectively.

One drawback of the in vivo use of scFvs is low retention on the target and rapid off rates, due to their monovalency. This can be especially pronounced in the non-equilibrium environment of tumor vasculatures [5]. Their small sizes, though a desirable property for tissue penetration, such as in cancer therapy, also leads to a short in vivo half-life, limiting the exposure of the target molecule to the scFv. These issues have been addressed by genetically manipulating and engineering scFvs to yield 
multivalent and multifunctional multimers (diabodies, triabodies and tetrabodies) that have higher avidity and lower blood clearance, without compromising tissue penetration abilities [7]. For instance, it has been argued that the optimal tumor-targeting fragment would be a diabody ( $55 \mathrm{kDa}$ ) combining high tissue penetration, target retention and rapid blood clearance [28,29]. Moreover, scFv fragments can be further engineered so that they are linked to different moieties, such as drugs, toxins, radionuclides, quantum dots or liposomes [5,24,30-32]. The application of ScFv fragments is therefore quite broad, including use as molecular tools to perturb protein functions in vivo [33,34], delivery agents of radionuclides in diagnostic imaging [26,27] and as potential therapeutics for several diseases, including cancer, HIV and neurodegenerative diseases [13,25,35,36].

Traditionally scFvs were produced from hybridoma cells obtained from immunized animals by amplifying the $\mathrm{V}_{\mathrm{H}}$ and $\mathrm{V}_{\mathrm{L}}$ domains from the mRNA and joining them with a poly linker, after which they can be inserted in a vector of choice [33] (Figure 2). Recently, in vitro display technologies (phage, yeast) have taken over hybridoma technology, because of their adaptability to high throughput formats. They can also be manipulated to optimize $\mathrm{scFv}$ properties and generate a population of extremely diverse and highly functional antibodies [37,38]. These in vitro displays can be obtained either from natural or synthetic antibody libraries [37]. Synthetic antibody libraries specially eliminate the need to obtain antibodies from immunized host and also enable the introduction of extreme diversity in the scFvs, as they allow manipulating the CDR regions through synthetic DNA [37,38].

Figure 1. (a) Schematic representation of full-length monoclonal antibodies $(\mathrm{mAb})$ and single chain variable domain (Fv) fragments (scFv) fragments. (b) scFv fragments can be engineered into multivalent species: diabody, triabody and tetrabody.
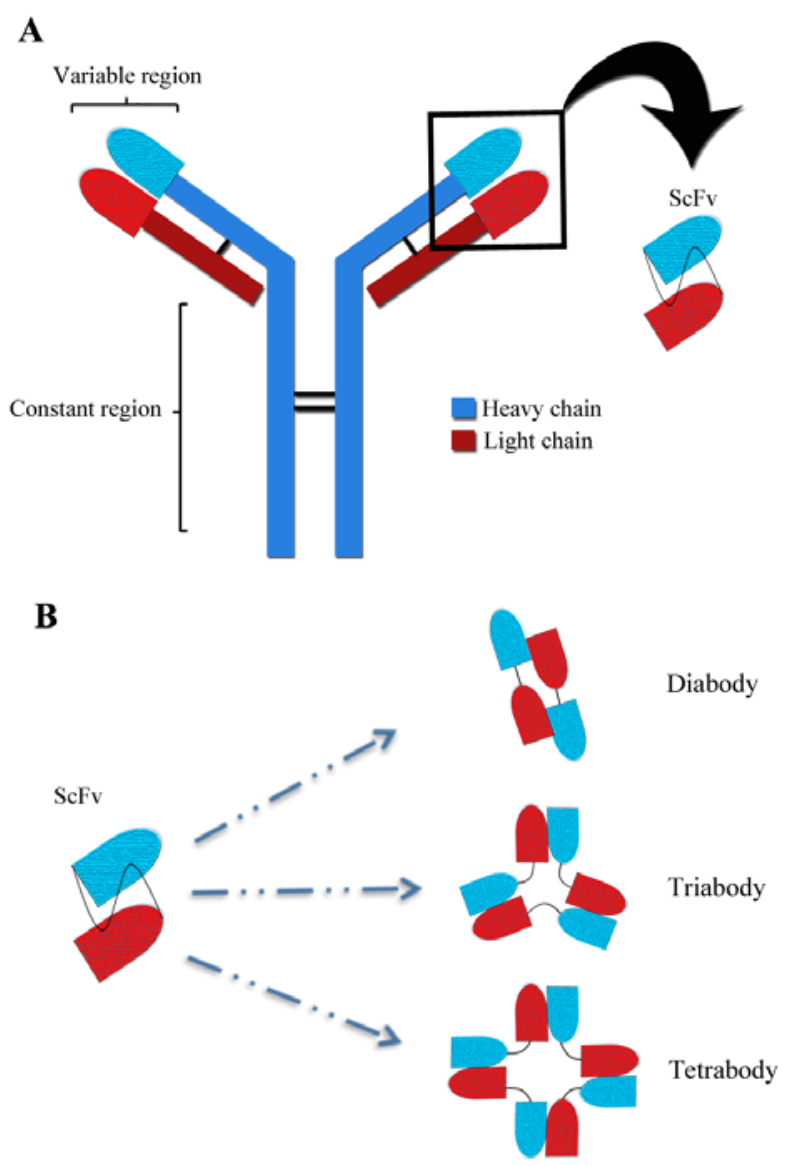


\section{In Vivo Delivery}

In vivo application of scFvs necessitates the choice of an appropriate $\mathrm{scFv}$ administration route, vehicle of delivery, maintenance of adequate concentration and toxicity effects. ScFvs can be produced and injected systemically, or they can be delivered using viral vectors and overexpressed in vivo. ScFvs can be produced using different cell systems, purified, tagged when necessary and systemically administered. This mode of delivery is useful when long-term expression is not required, for instance, in imaging applications. However, in cases where sustained level of antibody is required, viral mediated delivery provides an alternative. In the effort to develop $\mathrm{scFv}$ therapeutics for neurodegenerative diseases where the target is in the brain, a major challenge has been the difficulty of crossing the blood-brain barrier to deliver the therapy. Progress has been made in this area by tailoring scFvs to enhance their uptake by the brain. Viral mediated scFv delivery and enhancement of crossing of the blood brain barrier will be discussed briefly.

\subsection{Viral Mediated Delivery}

In order to sustain the expression of antibody fragments over long periods, scFvs can be cloned in a viral vector and delivered by injection of the virus (Figure 2). The adeno-associated virus (AAV) vector has been the most commonly used mode of scFv delivery compared to other viruses. The AAV is non-pathogenic, non-toxic and has low immunogenicity [39]. The use of other viral vectors is limited, due to some non-desirable properties. One advantage of the AAV is the ability to insert itself into the host genome at a specific locus resulting in a low frequency of random insertions. In contrast, for instance, retroviruses can insert at random sites, leading to mutagenesis and cancer. The AAV virus has a wide spread tropism and can infect both dividing and non-dividing cells, including neurons [39-41]. The most widely used serotype is AAV2, but AAV1, AAV5 and AAV8 have also been employed [42]. The challenge of delivering $\mathrm{mAbs}$ via $\mathrm{AAV}$ is the size restriction placed by what can be packaged by the virus. For AAV2 virus, the upper limit is $5 \mathrm{~kb}$, and larger proteins are not efficiently expressed [39]. For expression of scFvs in avian cells, the replication-competent retroviral vector (RCASBP) has been used for long-term expression in the developing chick brain [33]. In this vector, genes longer than $2 \mathrm{~kb}$ are not efficiently expressed [43]. ScFvs do not suffer from this drawback compared to the larger size $\mathrm{mAbs}$, and high-level long-term expression has been achieved in several animal models.

\subsection{ScFv Linked to a Blood-Brain Barrier (BBB) Receptor Antibody}

The therapeutic potential of antibodies to treat neurodegenerative diseases is limited, due to the difficulty of crossing the blood-brain barrier (BBB) and reaching target antigens in the brain. Very high doses of a therapeutic antibody have to be administered systemically in order for very small amounts (only $0.1-1 \%$ of plasma levels) to be detected in the brain, thus necessitating that they be administered intracranially $[44,45]$. To improve BBB permeability, receptor-mediated transcytosis has been employed, where an antibody against an endogenous BBB receptor-mediated transport protein is linked to scFvs to increase transport across the endothelial cell barrier (Figure 3). To this end chimeric antibodies have been engineered in which scFvs are linked to antibodies against transferrin receptor (TIR) or human insulin receptor (HIR), which are highly expressed by endothelial cells that make up 
the BBB [46-49]. The TIR or HIR receptor antibody binds to the receptor on the BBB, leading to the release of scFvs in the brain. The efficiency of scFv release after crossing the BBB is another area to be researched, but regardless, this method is a promising avenue to deliver therapeutics to many neurodegenerative diseases where the target is in the brain. For instance, as a potential therapy in Alzheimer's disease, peripherally administered scFv-TIR conjugates reduced the level of amyloid plaques in the brain of mouse models, and antibodies were detected in the brain [46-49].

Figure 2. Schematic representation of the process by which scFvs are generated from hybridoma cells and injected in the developing chick brain. Mice were immunized with [3] antigens from the $\mathrm{N}$ - and $\mathrm{C}$-terminal parts of repulsive guidance molecule (RGMa) and antibodies generated. The $\mathrm{V}_{\mathrm{H}}$ and $\mathrm{V}_{\mathrm{L}}$ regions were amplified from the hybridoma mRNA, linked and cloned in the replication-competent retroviral vector (RCASBPB) vector. Virus was produced in DF1 cells and injected in the optic tectum of the chick embryo at E2 (Embryonic day 2). A DiI dye was implanted at E15 in the eye to trace the fibers targeting the tectum. Embryos were sacrificed two days later, and tracing revealed that retinal fibers displayed targeting errors in the tectum, due to neutralization of the RGMa domains [33].

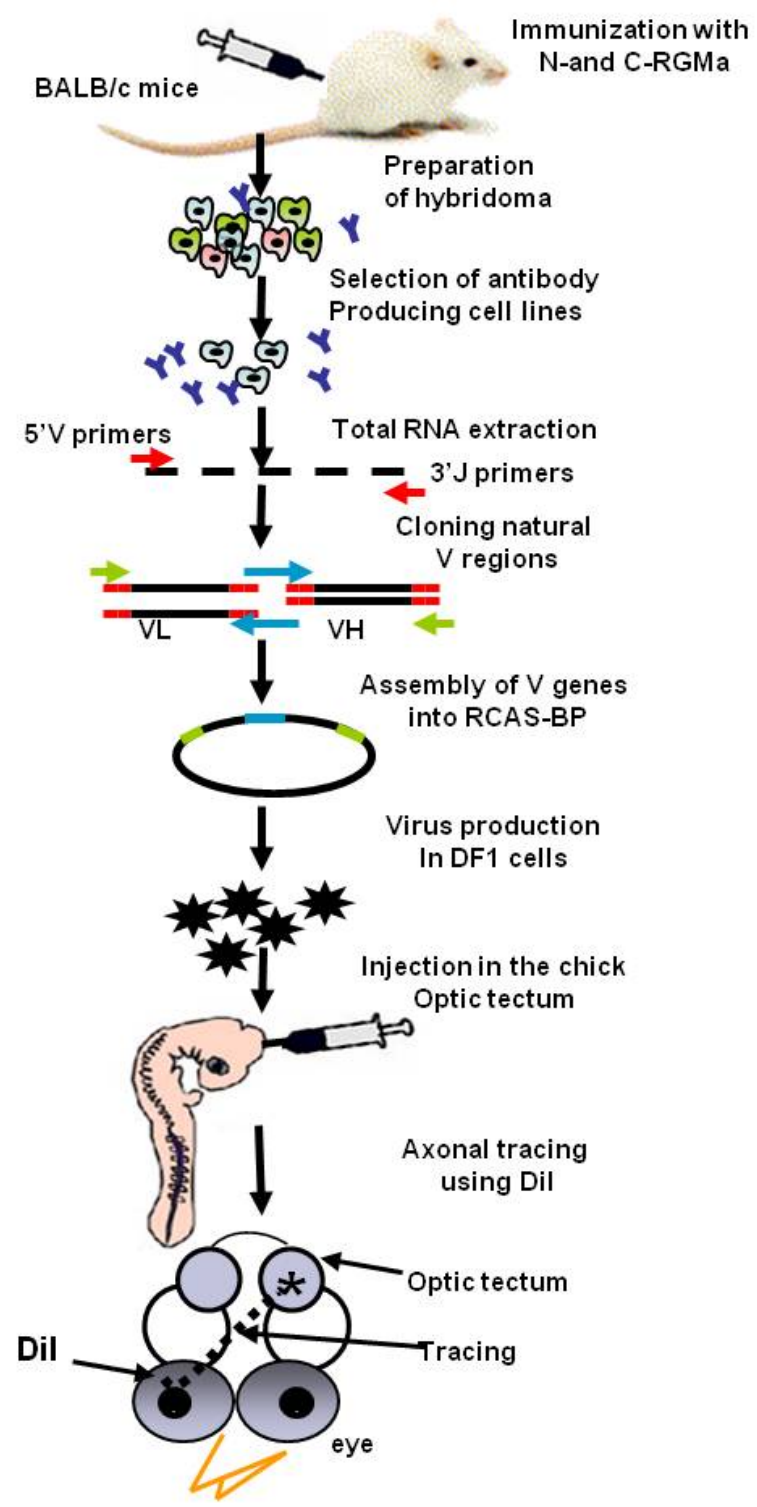


Figure 3. The scFv fragment is linked to the carboxy terminus of an antibody targeting the transferrin receptor (TIR), which is highly expressed by endothelial cells. The scFv crosses the blood-brain barrier through receptor-mediated transcytosis.

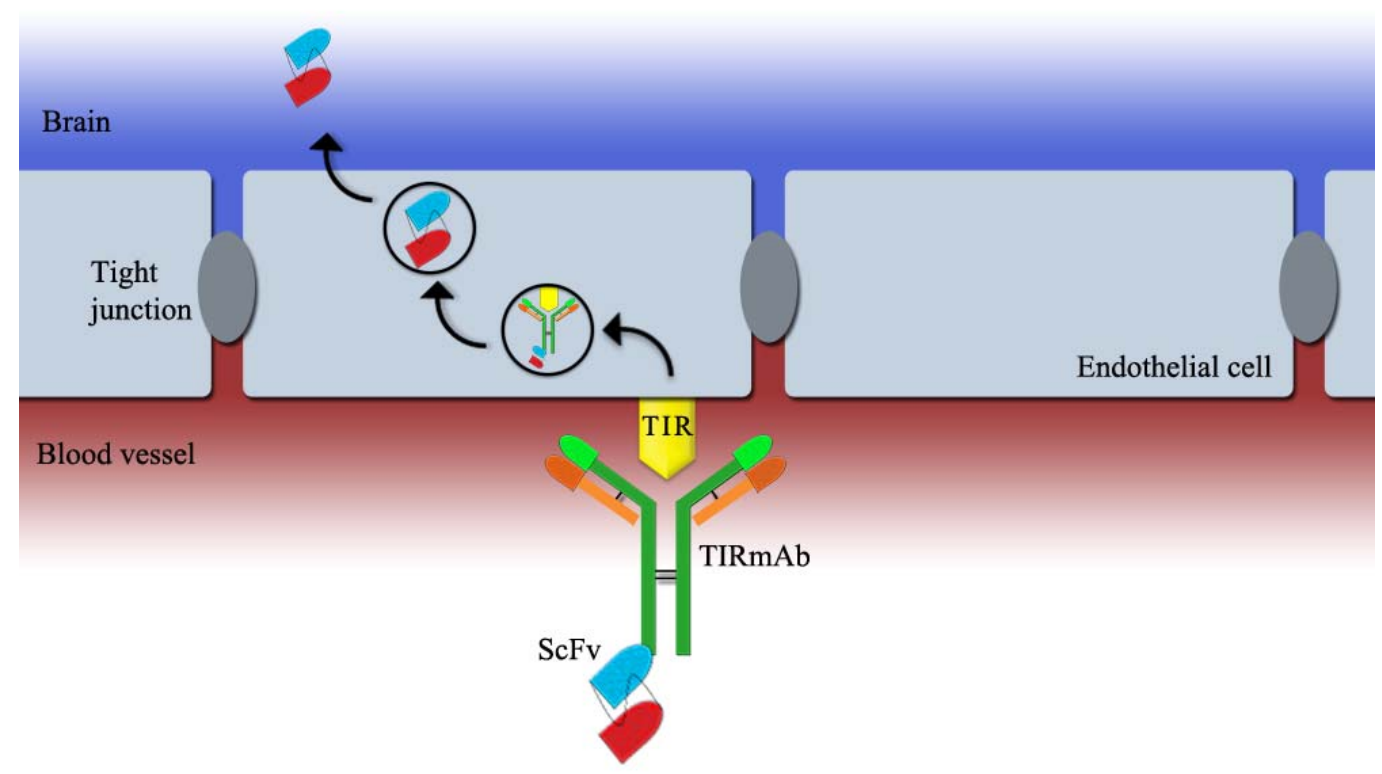

\section{In Vivo Application of scFv Fragments}

\subsection{A Tool to Study Protein Functions}

ScFvs provide a means to carry out loss-of-function studies in vivo animal models. They can be especially useful when only part of a protein needs to be studied. RNA interference (RNAi) technologies that are routinely used for the above function downregulate the entire protein, thus preventing the study of individual domains. In addition, RNAi technologies for in vivo use have faced challenges when it comes to delivery to the specific target tissue, as well as the existence of undesirable off-target toxic effects [39,50]. However, in vivo use of scFvs can overcome these limitations, since scFvs can be targeted to either a specific part or the entire protein. ScFv delivery via a viral vector eliminates the need for multiple administrations, and antibody concentration can be maintained to sustain silencing. These fragments have been shown to be useful for in vivo loss-of-function studies and have helped elucidate protein functions [33,34,40].

In the developing chick visual system, the long-term in vivo expression of scFvs was obtained through RCASBP virus-mediated delivery [33]. Hybridoma cells were obtained from mice immunized with antigens from the $\mathrm{N}$ - and $\mathrm{C}$ - domains of the repulsive guidance molecule (RGMa). ScFvs were generated and cloned in RCASBP and injected in the tectum of chick embryos (Figure 3). The scFvs were cloned with a 6His-tag, and the maintenance of antibody expression and spreading of the virus for the duration of the experiment (E2.5 to E17) was demonstrated by immunostaining for His-tag and the viral protein, gag. The recombinant antibody fragments were efficiently secreted and neutralized 
RGMa domains, as axonal pathfinding phenotypes were observed in retinal axons failing to target their correct positions in the optic tectum [33]. This method allowed the dissection of RGMa domain functions in axon guidance, which would not have been possible with RNAi techniques. The use of full-length antibodies would also have limitations in this respect, as it would have to be administered several times for the duration of the experiment, since it cannot be packaged in a viral vector.

In another study, loss-of-function using scFvs were performed to dissect the activity of Pax6 on migrating oligodendrocyte precursor cells (OPC) in the developing chick CNS [34]. A plasmid encoding a neutralizing scFv against the extracellular domain of Pax6 was electroporated in the neural tube. The scFv was able to neutralize the extracellular domain of Pax6, resulting in decreased migration of OPCs, highlighting the involvement of the extracellular domain of Pax6.

Thus, scFv fragments offer a means of elucidating in vivo protein functions and may overcome the limitations associated with RNAi and mAb techniques for in vivo use.

\subsection{Cancer Therapy}

Monoclonal antibodies can recognize specific markers expressed on tumor cells and have been explored as treatments for cancer [25,51]. However, their use in solid tumors is limited, because of poor tissue penetration abilities [25]. ScFv fragments exhibit better tissue penetration, but are rapidly cleared from blood, compromising their ability to concentrate in the tumor, and have reduced affinity, due to their small size and monovalent binding, respectively [52]. Efforts to reduce blood clearance included conjugating scFvs to polyethylene glycol to increase their molecular size and hydrodynamic radius [53,54], dimerization of scFvs by incorporating C-terminal cysteines in order to form $\mathrm{scFv}$ multimers (diabodies; $60 \mathrm{kDa}$, triabodies; $90 \mathrm{kDa}$, tetrabodies; $120 \mathrm{kDa}$ ), which improved affinity and reduced renal clearance [52]. However, the increase in size, though, slows scFv clearance from blood; it may also compromise tissue penetration, and the two characteristics have to be balanced for effective tumor therapy. In this regard, diabodies outperform monomeric scFvs with a better tumor blood ratio [52]. Thus, recombinant antibodies of $60-100 \mathrm{kDa}$ have been found to display efficient tumor penetration and fast circulation clearance compared to the intact antibody and are thus better suited for in vivo tumor targeting.

Tumor therapy using scFvs requires targeting specific markers on tumor cells and either neutralizing the specific protein or effectively delivering another therapeutic entity, such as a toxin, drug or siRNA. For example, the CC chemokine receptor 4 (CCR4) ligands are highly expressed in several cancers, such as breast cancer, ovarian cancer and cutaneous T-cell lymphoma [42,55,56], and can be targeted for tumor-therapy [42]. This was explored as a potential treatment for cutaneous T-cell lymphoma in which a minibody was encoded in AAV and delivered in a single intravenous injection [42]. A long-lasting and high level expression of the antibody was sustained and resulted in anti-tumor activity against CCR4+ bearing tumor cells [42].

ScFvs have also been recently developed as recombinant immunotoxins (RIT) to carry cytotoxic drugs to kill cancer cells [57,58]. This is achieved by replacing the cell-binding domain of Pseudomonas exotoxin A with an scFv that binds to an antigen on cancer cells [57]. Three such RITs, either alone or in combination with chemotherapy, are undergoing clinical trials for different types of cancer malignancies $[58,59]$. 
Another area that is being explored in scFv-mediated cancer therapy is using them as cancer vaccines in immunogenic tumors. For instance, epidermal growth factor receptor 2 (HER2) has been targeted in breast cancer therapy, as it is overexpressed in $20 \%$ of invasive breast cancer cases $[35,60]$. Thus, conferring anti-HER2 immunity has been pursued as a promising therapy. ScFvs have been used in this regard, and vaccinations with anti-HER2 scFvs have been shown to result in a robust humoral response and delay in the onset of breast tumors in mice [60].

\subsection{Neurodegenerative Diseases}

\subsubsection{Alzheimer's Disease (AD)}

Alzheimer's disease (AD) is characterized by progressive memory deficits and cognitive impairments. There is no cure for $\mathrm{AD}$, and so far, treatments only slow the progression of the disease and ameliorate some of the symptoms. The $4 \mathrm{kDa} A \beta$ peptide resulting from the cleavage of the amyloid precursor protein is considered a potential target for AD therapy [61]. This peptide is prone to self-aggregation, forming neurotoxic species, and therapies are aimed at reversing the formation of these aggregates [62]. Clinical trials involving active immunization therapies using $A \beta$ peptide, though, cleared away toxic plaques and slowed cognitive decline among treated patients compared to control groups, had undesirable side effects induced by T-cell-mediated and/or Fc-mediated meningoencephalitis and were abandoned $[63,64]$. Passive immunization with A $\beta$ antibodies showed clearance of $\mathrm{A} \beta$ deposits in mouse models and may be potentially developed for AD therapy [36]. However, this mode of administration would require repeated injections and may not be ideal for human therapy. Thus, alternative strategies that involve engineered antibodies that do not contain the Fc fragment and can be overexpressed long-term in vivo, eliminating the need for repeated injections, became attractive. Thus, ScFvs have evolved as potential therapeutic venues for the treatment of $\mathrm{AD}$ [65]. In addition to being efficiently expressed in several systems leading to high production and lower cost, scFvs may also cross the blood brain barrier, even in cases where they are peripherally administered [66,67].

The main mode of administering scFvs for AD therapy is intracranial injection using adeno-associated virus (AAV) vector. ScFvs with high immunoreactivity against the $A \beta$ were identified through screening of human scFv libraries and were delivered in the brains of transgenic mouse models of $\mathrm{AD}[68,69]$. Anti $\mathrm{A} \beta \mathrm{scFvs}$ have been shown to reduce amyloid plaques, and treated mice had lower amyloid plaques and scored better on functional tests compared to control groups [68,69]. AAV mediated overexpression of scFvs enables long-term in vivo expression, and antibodies were detected in the brain a year after injection without causing neurotoxicity [68].

Though successful in mice, less invasive $s c F v$ delivery routes are required for human therapies, and other modes of administration have been explored. Intramuscularly-administered scFvs against A $\beta$ have been shown to be successful in reducing amyloid plaques and in improving cognitive impairments in AD mouse models $[66,67,70]$. ScFvs were detected in the brain several months after viral-mediated administration and effectively reduced amyloid plaques. Intranasal delivery of scFvs has also been explored as a possible route of administration as a means of avoiding the blood-brain 
barrier and clearance from circulation [71]. ScFvs directed against the C-terminus of A $\beta$ were intranasally delivered and entered the brain, leading to reduction of $\mathrm{A} \beta$ accumulation.

\subsubsection{Huntington's Disease (HD)}

$\mathrm{HD}$ is a neurodegenerative disease that is characterized by abnormal folding and proteolytic cleavage of the mutant huntingtin protein (mHTT) to N-terminal fragments, leading to formation of aggregates and neuronal and neuropil inclusion bodies in the brain [72]. To reduce the levels of mHTT, RNAi interference and protein-based techniques have been employed. RNAi-based approaches may have limitations when it comes to off-target toxic effects and non-specificity for the mutant protein [39]. ScFvs show less off-target effects and can target the mHTT protein based on conformational differences with the wild-type protein [39]. Such scFvs have been generated that preferentially bind to different regions in the amino terminal of mHTT fragments compared to the full HTT and led to a reduction of aggregates [39,73-76].

The normal mode of scFv delivery for HD therapy has been intracranial injections using AAV virus in mouse models [74,75]. For these scFv-based HD therapies to be of use in clinical applications, systematic administration and getting the therapy in the brain are issues that need to be addressed.

The ideal antibody therapy to treat neurodegenerative diseases would be peripheral administration of antibodies that can cross the blood-brain barrier in adequate amounts and be efficiently released in brain areas to maintain therapeutic concentrations. Efforts are underway to genetically engineer scFvs to enhance their uptake by the brain. With new developments in delivering scFvs in the brain using receptor-mediated transcytosis, there is still more to be done to ensure that scFvs are efficiently released once they cross the blood-brain barrier [48].

\subsection{In Vivo Imaging}

The small size of scFvs enables genetic manipulations to conjugate them with radionuclei, quantum dots, nanoparticles, etc. [26,27]. Thus, they can provide a non-invasive tool to visualize the location and distribution of a specific target in vivo. To this aim, an optimal pharmacokinetics is critical and should balance deep tissue penetration and optimal clearance from blood without compromising binding affinity. The scFv format is the ideal imaging tool among the other antibody fragments, since it combines all of the above properties. Though the faster clearance of scFvs poses challenges for therapeutic applications, it is a much desired property when it comes to in vivo diagnostic applications. For instance, this has been shown in imaging of heart disease using site-specific ${ }^{111}$ In labeled scFv fragments against tenascin-c in a myocardial infarction rat model [27]. Radiolabelled scFv specifically bound to tenascin-c, and higher uptake of radioactivity was seen in infarcted myocardium compared to the non-infarcted one. In addition, a much lower amount of radioactivity (about three-times less per gram of body weight) remained at $6 \mathrm{~h}$ after ${ }^{111} \mathrm{In}-\mathrm{scFv}$ injection compared to similarly labeled Fab [27].

scFvs have been attached to fluorescent moieties and have been employed to image a target tissue [77,78]. For instance, scFv was conjugated to quantum dots and delivered in a xenograft mouse model [78]. The scFv was targeted against GRP78, a protein that is expressed by various cancers and has roles in cell proliferation and angiogenesis [79]. The quantum dot conjugated scFv enabled easy visualization of the in vivo target, as well as inhibiting breast tumor growth. Also in another study, 
anti-tumor scFvs (425 scFv and 4D5 scFv), which bind to oncomarkers, HER1 EGFR and HER2/neu, respectively, were conjugated to quantum dots and enabled visualization of cancer cells [77]. This study was done in vitro using cells that overexpress the oncomarkers; however, it illustrates the point that scFvs allow for targeting and visualization of specific tissues in vivo.

Another emerging area of scFv use is in the magnetic resonance imaging (MRI) field [80,81]. The sensitivity of MRI imaging has been shown to improve by conjugating scFvs with supramagnetic iron oxide nanoparticles (SPIONs). For instance, in imaging of tumors, SPIONs provide contrast between healthy and cancerous cells, due to a differential uptake. Thus, by conjugating scFvs with SPIONs, specific cells can be targeted, improving the sensitivity of MRI. In a study, scFvs against carcinoembryonic antigen was attached to SPIONs, and it was demonstrated that a selective image contrast was obtained on MRI highlighting the potential of scFvs to improve specificity of targeting cancer cells.

\subsection{Vehicles to Deliver Drugs/Nanoparticles}

The application of scFvs as vehicles to deliver therapeutics is an emerging area for the development of immunotherapeutics for several diseases. The specific target recognition of scFvs combined with high levels of expression via viruses makes them useful tools to deliver drugs, siRNA and toxins to immune cells and tumors [82,83]. For instance, this has been shown in HIV-infected mice, in which anti-viral siRNA was coupled to a CD7 targeting scFv and was administered systematically [82]. This resulted in lower viral replication.

Another emerging application is the use of scFvs as immuno-nanoparticles for the delivery of drugs to a specific target. Chio el al. [84] have shown that latent HIV, which hides in CD4+ T-cells, can be targeted by delivering histine deacetylase inhibitor (HDACi) by covalently binding scFvCD7 with PLGA (a biodegradable polymer) that is loaded with HDACi. This method showed specificity, as the immuno-nanoparticles were only delivered to the T-cell targets and enabled the sustained release of HDACi. This work was done using human cells and needs to be shown in vivo. However, it highlights the potential of scFvs to be used as delivery vehicles.

\section{Conclusions}

Since their introduction in 1988, scFvs have become highly relevant in pre-clinical and clinical applications and research laboratories. Advances in antibody engineering have made possible the generation of highly tailored scFvs that have improved pharmacokinetic properties, making them more clinically relevant. A trend to couple these recombinant antibodies to different moieties has broadened their potential in diagnostic, therapeutic and in vivo imaging applications. Still, several challenges remain to be addressed in their in vivo use. Their small size, though advantageous for in vivo imaging, is undesirable for therapeutic applications, since it makes them unstable and prevents accumulation of scFvs at the target site. There are efforts to increase their in vivo half-life and stability though various modifications, such as PEGylation. However, certain technical challenges need to be overcome to produce them cost-effectively in this format. The lack of Fc leads to low immunogenicity; however, it also limits their therapeutic potential, since they can only exert their functions though binding to the target and cannot induce Fc-mediated cytotoxicity. Thus, they have to be conjugated to drugs and 
toxins to be more effective in therapies. Even with the above challenges, these fragments are bound to become more relevant in the development of therapeutics for cancer, neurodegenerative and immunological diseases, due to their favorable properties.

\section{Acknowledgments}

We would like to thank Paromita Banerjee and Jason Charish for helping with the editing of this manuscript and making useful recommendations.

\section{References}

1. Ward, E.S.; Martinez, C.; Vaccaro, C.; Zhou, J.; Tang, Q.; Ober, R.J. From sorting endosomes to exocytosis: Association of Rab4 and Rab11 GTPases with the Fc receptor, FcRn, During recycling. Mol. Biol. Cell 2005, 16, 2028-2038.

2. Woof, J.M.; Burton, D.R. Human antibody-Fc receptor interactions illuminated by crystal structures. Nat. Rev. Immunol. 2004, 4, 89-99.

3. Adams, G.P.; Weiner, L.M. Monoclonal antibody therapy of cancer. Nat. Biotechnol. 2005, 23, $1147-1157$.

4. Wu, A.M.; Senter, P.D. Arming antibodies: Prospects and challenges for immunoconjugates. Nat. Biotechnol. 2005, 23, 1137-1146.

5. Holliger, P.; Hudson, P.J. Engineered antibody fragments and the rise of single domains. Nat. Biotechnol. 2005, 23, 1126-1136.

6. Porter, R.R. The hydrolysis of rabbit y-globulin and antibodies with crystalline papain. Biochem. J. 1959, 73, 119-126.

7. Hudson, P.J. Recombinant antibody fragments. Curr. Opin. Biotechnol. 1998, 9, 395-402.

8. Little, M.; Kipriyanov, S.M.; le Gall, F.; Moldenhauer, G. Of mice and men: Hybridoma and recombinant antibodies. Immunol. Today 2000, 21, 364-370.

9. Skerra, A.; Pluckthun, A. Assembly of a functional immunoglobulin Fv fragment in Escherichia coli. Science 1988, 240, 1038-1041.

10. Hust, M.; Jostock, T.; Menzel, C.; Voedisch, B.; Mohr, A.; Brenneis, M.; Kirsch, M.I.; Meier, D.; Dubel, S. Single chain Fab (scFab) fragment. BMC Biotechnol. 2007, 7, 14.

11. Edwardraja, S.; Sriram, S.; Govindan, R.; Budisa, N.; Lee, S.G. Enhancing the thermal stability of a single-chain Fv fragment by in vivo global fluorination of the proline residues. Mol. Biosyst. 2011, 7, 258-265.

12. Nelson, A.L. Antibody fragments: Hope and hype. MAbs 2010, 2, 77-83.

13. Nelson, A.L.; Reichert, J.M. Development trends for therapeutic antibody fragments. Nat. Biotechnol. 2009, 27, 331-337.

14. Maynard, J.; Georgiou, G. Antibody engineering. Annu. Rev. Biomed. Eng. 2000, 2, 339-376.

15. Bird, R.E.; Hardman, K.D.; Jacobson, J.W.; Johnson, S.; Kaufman, B.M.; Lee, S.M.; Lee, T.; Pope, S.H.; Riordan, G.S.; Whitlow, M. Single-chain antigen-binding proteins. Science 1988, 242, 423-426. 
16. Huston, J.S.; Levinson, D.; Mudgett-Hunter, M.; Tai, M.S.; Novotny, J.; Margolies, M.N.; Ridge, R.J.; Bruccoleri, R.E.; Haber, E.; Crea, R.; et al. Protein engineering of antibody binding sites: Recovery of specific activity in an anti-digoxin single-chain Fv analogue produced in Escherichia coli. Proc. Natl. Acad. Sci. USA 1988, 85, 5879-5883.

17. Ahmad, Z.A.; Yeap, S.K.; Ali, A.M.; Ho, W.Y.; Alitheen, N.B.; Hamid, M. scFv antibody: Principles and clinical application. Dev. Immunol. 2012, $2012,980250$.

18. Whitlow, M.; Bell, B.A.; Feng, S.L.; Filpula, D.; Hardman, K.D.; Hubert, S.L.; Rollence, M.L.; Wood, J.F.; Schott, M.E.; Milenic, D.E.; et al. An improved linker for single-chain Fv with reduced aggregation and enhanced proteolytic stability. Protein Eng. 1993, 6, 989-995.

19. Alfthan, K.; Takkinen, K.; Sizmann, D.; Soderlund, H.; Teeri, T.T. Properties of a single-chain antibody containing different linker peptides. Protein Eng. 1995, 8, 725-731.

20. Baneyx, F. Recombinant protein expression in Escherichia coli. Curr. Opin. Biotechnol. 1999, 10, 411-421.

21. Ho, M.; Nagata, S.; Pastan, I. Isolation of anti-CD22 Fv with high affinity by Fv display on human cells. Proc. Natl. Acad. Sci. USA 2006, 103, 9637-9642.

22. Galeffi, P.; Lombardi, A.; Pietraforte, I.; Novelli, F.; Di Donato, M.; Sperandei, M.; Tornambe, A.; Fraioli, R.; Martayan, A.; Natali, P.G.; et al. Functional expression of a single-chain antibody to ErbB-2 in plants and cell-free systems. J. Transl. Med. 2006, 4, 39.

23. Choo, A.B.; Dunn, R.D.; Broady, K.W.; Raison, R.L. Soluble expression of a functional recombinant cytolytic immunotoxin in insect cells. Protein Expres. Purif. 2002, 24, 338-347.

24. Chowdhury, P.S.; Viner, J.L.; Beers, R.; Pastan, I. Isolation of a high-affinity stable single-chain Fv specific for mesothelin from DNA-immunized mice by phage display and construction of a recombinant immunotoxin with anti-tumor activity. Proc. National. Acad. Sci. USA 1998, 95, $669-674$.

25. Deckert, P.M. Current constructs and targets in clinical development for antibody-based cancer therapy. Curr. Drug Targets 2009, 10, 158-175.

26. Cheng, K.T. Radioiodinated-anti-TAG-72 covalently linked CC49 divalent single-chain Fv antibody. In Molecular Imaging and Contrast Agent Database (MICAD); National Center for Biotechnology Information: Bethesda, MD, USA, 2004.

27. Kobayashi, N.; Odaka, K.; Uehara, T.; Imanaka-Yoshida, K.; Kato, Y.; Oyama, H.; Tadokoro, H.; Akizawa, H.; Tanada, S.; Hiroe, M.; et al. Toward in vivo imaging of heart disease using a radiolabeled single-chain Fv fragment targeting tenascin-C. Anal. Chem. 2011, 83, 9123-9130.

28. Robinson, M.K.; Doss, M.; Shaller, C.; Narayanan, D.; Marks, J.D.; Adler, L.P.; Gonzalez Trotter, D.E.; Adams, G.P. Quantitative immuno-positron emission tomography imaging of HER2-positive tumor xenografts with an iodine-124 labeled anti-HER2 diabody. Cancer Res. 2005, 65, 1471-1478.

29. Sundaresan, G.; Yazaki, P.J.; Shively, J.E.; Finn, R.D.; Larson, S.M.; Raubitschek, A.A.; Williams, L.E.; Chatziioannou, A.F.; Gambhir, S.S.; Wu, A.M. 124I-labeled engineered antiCEAcea minibodies and diabodies allow high-contrast, antigen-specific small-animal PETimaging of xenografts in athymic mice. J. Nucl. Med. 2003, 44, 1962-1969.

30. Chari, R.V. Targeted delivery of chemotherapeutics: Tumor-activated prodrug therapy. Adv. Drug Deliv. Rev. 1998, 31, 89-104. 
31. Gattenlohner, S.; Jorissen, H.; Huhn, M.; Vincent, A.; Beeson, D.; Tzartos, S.; Mamalaki, A.; Etschmann, B.; Muller-Hermelink, H.K.; Koscielniak, E.; et al. A human recombinant autoantibody-based immunotoxin specific for the fetal acetylcholine receptor inhibits rhabdomyosarcoma growth in vitro and in a murine transplantation model. J. Biomed. Biotechnol. 2010, 2010, 187621.

32. Tong, Q.; Liu, K.; Lu, X.M.; Shu, X.G.; Wang, G.B. Construction and characterization of a novel fusion protein MG7-scFv/SEB against gastric cancer. J. Biomed. Biotechnol. 2010, 2010, 121094.

33. Tassew, N.G.; Charish, J.; Chestopalova, L.; Monnier, P.P. Sustained in vivo inhibition of protein domains using single-chain Fv recombinant antibodies and its application to dissect rgma activity on axonal outgrowth. J. Neurosci. 2009, 29, 1126-1131.

34. Di Lullo, E.; Haton, C.; Le Poupon, C.; Volovitch, M.; Joliot, A.; Thomas, J.L.; Prochiantz, A. Paracrine Pax6 activity regulates oligodendrocyte precursor cell migration in the chick embryonic neural tube. Development 2011, 138, 4991-5001.

35. Curigliano, G.; Spitaleri, G.; Dettori, M.; Locatelli, M.; Scarano, E.; Goldhirsch, A. Vaccine immunotherapy in breast cancer treatment: Promising, but still early. Expert Rev. Anticancer Ther. 2007, 7, 1225-1241.

36. Bard, F.; Cannon, C.; Barbour, R.; Burke, R.L.; Games, D.; Grajeda, H.; Guido, T.; Hu, K.; Huang, J.; Johnson-Wood, K.; et al. Peripherally administered antibodies against amyloid beta-peptide enter the central nervous system and reduce pathology in a mouse model of Alzheimer disease. Nat. Med. 2000, 6, 916-919.

37. Sidhu, S.S.; Fellouse, F.A. Synthetic therapeutic antibodies. Nat .Chem .Biol. 2006, 2, 682-688.

38. Bradbury, A.R.; Sidhu, S.; Dubel, S.; McCafferty, J. Beyond natural antibodies: The power of in vitro display technologies. Nat. Biotechnol. 2011, 29, 245-254.

39. Butler, D.C.; McLear, J.A.; Messer, A. Engineered antibody therapies to counteract mutant huntingtin and related toxic intracellular proteins. Prog. Neurobiol. 2012, 97, 190-204.

40. Zuber, C.; Mitteregger, G.; Schuhmann, N.; Rey, C.; Knackmuss, S.; Rupprecht, W.; Reusch, U.; Pace, C.; Little, M.; Kretzschmar, H.A.; et al. Delivery of single-chain antibodies (scFvs) directed against the $37 / 67 \mathrm{kDa}$ laminin receptor into mice via recombinant adeno-associated viral vectors for prion disease gene therapy. J. Gen. Virol. 2008, 89, 2055-2061.

41. Daya, S.; Berns, K.I. Gene therapy using adeno-associated virus vectors. Clin. Microbiol. Rev. 2008, 21, 583-593.

42. Han, T.; Abdel-Motal, U.M.; Chang, D.K.; Sui, J.; Muvaffak, A.; Campbell, J.; Zhu, Q.; Kupper, T.S.; Marasco, W.A. Human anti-CCR4 minibody gene transfer for the treatment of cutaneous t-cell lymphoma. PLoS One 2012, 7, e44455.

43. Hughes, S.H.; Greenhouse, J.J.; Petropoulos, C.J.; Sutrave, P. Adaptor plasmids simplify the insertion of foreign DNA into helper-independent retroviral vectors. J. Virol. 1987, 61, 3004-3012.

44. Atwal, J.K.; Chen, Y.; Chiu, C.; Mortensen, D.L.; Meilandt, W.J.; Liu, Y.; Heise, C.E.; Hoyte, K.; Luk, W.; Lu, Y.; et al. A therapeutic antibody targeting BACE1 inhibits amyloid-beta production in vivo. Sci. Transl. Med. 2011, 3, 84ra43.

45. Hock, C.; Konietzko, U.; Papassotiropoulos, A.; Wollmer, A.; Streffer, J.; von Rotz, R.C.; Davey, G.; Moritz, E.; Nitsch, R.M. Generation of antibodies specific for beta-amyloid by vaccination of patients with Alzheimer disease. Nat. Med. 2002, 8, 1270-1275. 
46. Boado, R.J.; Zhou, Q.H.; Lu, J.Z.; Hui, E.K.; Pardridge, W.M. Pharmacokinetics and brain uptake of a genetically engineered bifunctional fusion antibody targeting the mouse transferrin receptor. Mol. Pharm. 2010, 7, 237-244.

47. Boado, R.J.; Lu, J.Z.; Hui, E.K.; Pardridge, W.M. IgG-single chain Fv fusion protein therapeutic for Alzheimer's disease: Expression in $\mathrm{CHO}$ cells and pharmacokinetics and brain delivery in the rhesus monkey. Biotechnol. Bioeng. 2010, 105, 627-635.

48. Yu, Y.J.; Zhang, Y.; Kenrick, M.; Hoyte, K.; Luk, W.; Lu, Y.; Atwal, J.; Elliott, J.M.; Prabhu, S.; Watts, R.J. et al. Boosting brain uptake of a therapeutic antibody by reducing its affinity for a transcytosis target. Sci.Transl. Med. 2011, 3, 84ra44.

49. Skrlj, N.; Drevensek, G.; Hudoklin, S.; Romih, R.; Curin Serbec, V.; Dolinar, M. Recombinant single-chain antibody with the Trojan peptide penetratin positioned in the linker region enables cargo transfer across the blood-brain barrier. Appl. Biochem. Biotechnol. 2013, 169, 159-169.

50. Hogrefe, R.I.; Lebedev, A.V.; Zon, G.; Pirollo, K.F.; Rait, A.; Zhou, Q.; Yu, W.; Chang, E.H. Chemically modified short interfering hybrids (siHYBRIDS): Nanoimmunoliposome delivery in vitro and in vivo for RNAi of HER-2. Nucleos. Nucleot. Nucl. 2006, 25, 889-907.

51. Ferris, R.L.; Jaffee, E.M.; Ferrone, S. Tumor antigen-targeted, monoclonal antibody-based immunotherapy: Clinical response, cellular immunity, and immunoescape. J. Clin. Oncol. 2010, $28,4390-4399$.

52. Wan, L.; Zhu, S.; Zhu, J.; Yang, H.; Li, S.; Li, Y.; Cheng, J.; Lu, X. Production and characterization of a CD25-specific scFv-Fc antibody secreted from Pichia pastoris. Appl. Microbiol. Biotechnol. 2012, in press.

53. Yang, K.; Basu, A.; Wang, M.; Chintala, R.; Hsieh, M.C.; Liu, S.; Hua, J.; Zhang, Z.; Zhou, J.; Li, M.; et al. Tailoring structure-function and pharmacokinetic properties of single-chain Fv proteins by site-specific PEGylation. Protein Eng. 2003, 16, 761-770.

54. Tsutsumi, Y.; Onda, M.; Nagata, S.; Lee, B.; Kreitman, R.J.; Pastan, I. Site-specific chemical modification with polyethylene glycol of recombinant immunotoxin anti-TAC(Fv)-PE38 (LMB2) improves antitumor activity and reduces animal toxicity and immunogenicity. Proc. Natl. Acad. Sci.USA 2000, 97, 8548-8553.

55. Olkhanud, P.B.; Baatar, D.; Bodogai, M.; Hakim, F.; Gress, R.; Anderson, R.L.; Deng, J.; Xu, M.; Briest, S.; Biragyn, A. Breast cancer lung metastasis requires expression of chemokine receptor CCR4 and regulatory T cells. Cancer Res. 2009, 69, 5996-6004.

56. Curiel, T.J.; Coukos, G.; Zou, L.; Alvarez, X.; Cheng, P.; Mottram, P.; Evdemon-Hogan, M.; Conejo-Garcia, J.R.; Zhang, L.; Burow, M.; et al. Specific recruitment of regulatory $\mathrm{T}$ cells in ovarian carcinoma fosters immune privilege and predicts reduced survival. Nat. Med. 2004, 10, 942-949.

57. Liu, W.; Onda, M.; Lee, B.; Kreitman, R.J.; Hassan, R.; Xiang, L.; Pastan, I. Recombinant immunotoxin engineered for low immunogenicity and antigenicity by identifying and silencing human B-cell epitopes. Proc. Natl. Acad. Sci. USA 2012, 109, 11782-11787.

58. Kreitman, R.J.; Tallman, M.S.; Robak, T.; Coutre, S.; Wilson, W.H.; Stetler-Stevenson, M.; Fitzgerald, D.J.; Lechleider, R.; Pastan, I. Phase i trial of anti-CD22 recombinant immunotoxin moxetumomab pasudotox (CAT-8015 or HA22) in patients with hairy cell leukemia. J. Clin. Oncol. 2012, 30, 1822-1828. 
59. Hassan, R.; Bullock, S.; Premkumar, A.; Kreitman, R.J.; Kindler, H.; Willingham, M.C.; Pastan, I. Phase I study of SS1P, a recombinant anti-mesothelin immunotoxin given as a bolus i.V. Infusion to patients with mesothelin-expressing mesothelioma, ovarian, and pancreatic cancers. Clin. Cancer Res. 2007, 13, 5144-5149.

60. Soliman, H. Immunotherapy strategies in the treatment of breast cancer. Cancer Control 2013, 20, 17-21.

61. Karran, E.; Mercken, M.; De Strooper, B. The amyloid cascade hypothesis for Alzheimer's disease: An appraisal for the development of therapeutics. Nat. Rev. Drug Discov. 2011, 10, 698-712.

62. Grill, J.D.; Cummings, J.L. Current therapeutic targets for the treatment of Alzheimer's disease. Expert Rev. Neurother. 2010, 10, 711-728.

63. Check, E. Nerve inflammation halts trial for Alzheimer's drug. Nature 2002, 415, 462.

64. Orgogozo, J.M.; Gilman, S.; Dartigues, J.F.; Laurent, B.; Puel, M.; Kirby, L.C.; Jouanny, P.; Dubois, B.; Eisner, L.; Flitman, S.; et al. Subacute meningoencephalitis in a subset of patients with AD after abeta42 immunization. Neurology 2003, 61, 46-54.

65. Robert, R.; Wark, K.L. Engineered antibody approaches for Alzheimer's disease immunotherapy. Arch. Biochem. Biophys. 2012, 526, 132-138.

66. Wang, Y.J.; Gao, C.Y.; Yang, M.; Liu, X.H.; Sun, Y.; Pollard, A.; Dong, X.Y.; Wu, X.B.; Zhong, J.H.; Zhou, H.D.; et al. Intramuscular delivery of a single chain antibody gene prevents brain abeta deposition and cognitive impairment in a mouse model of Alzheimer's disease. Brain Behav. Immun. 2010, 24, 1281-1293.

67. Wang, Y.J.; Pollard, A.; Zhong, J.H.; Dong, X.Y.; Wu, X.B.; Zhou, H.D.; Zhou, X.F. Intramuscular delivery of a single chain antibody gene reduces brain abeta burden in a mouse model of Alzheimer's disease. Neurobiol. Aging 2009, 30, 364-376.

68. Fukuchi, K.; Tahara, K.; Kim, H.D.; Maxwell, J.A.; Lewis, T.L.; Accavitti-Loper, M.A.; Kim, H.; Ponnazhagan, S.; Lalonde, R. Anti-abeta single-chain antibody delivery via adeno-associated virus for treatment of Alzheimer's disease. Neurobiol. Dis. 2006, 23, 502-511.

69. Ryan, D.A.; Mastrangelo, M.A.; Narrow, W.C.; Sullivan, M.A.; Federoff, H.J.; Bowers, W.J. Abeta-directed single-chain antibody delivery via a serotype-1 AAV vector improves learning behavior and pathology in Alzheimer's disease mice. Mol. Ther. 2010, 18, 1471-1481.

70. Yang, J.; Pattanayak, A.; Song, M.; Kou, J.; Taguchi, H.; Paul, S.; Ponnazhagan, S.; Lalonde, R.; Fukuchi, K. Muscle-directed anti-abeta single-chain antibody delivery via AAV1 reduces cerebral abeta load in an Alzheimer's disease mouse model. J. Mol. Neurosci. 2013, 49, 277-288.

71. Cattepoel, S.; Hanenberg, M.; Kulic, L.; Nitsch, R.M. Chronic intranasal treatment with an antiabeta(30-42) scFv antibody ameliorates amyloid pathology in a transgenic mouse model of Alzheimer's disease. PLoS One 2011, 6, e18296.

72. Crook, Z.R.; Housman, D. Huntington's disease: Can mice lead the way to treatment? Neuron 2011, 69, 423-435.

73. Miller, T.W.; Zhou, C.; Gines, S.; MacDonald, M.E.; Mazarakis, N.D.; Bates, G.P.; Huston, J.S.; Messer, A. A human single-chain v intrabody preferentially targets amino-terminal Huntingtin's fragments in striatal models of Huntington's disease. Neurobiol. Dis. 2005, 19, 47-56.

74. Butler, D.C.; Messer, A. Bifunctional anti-huntingtin proteasome-directed intrabodies mediate efficient degradation of mutant huntingtin exon 1 protein fragments. PLoS One 2011, 6, e29199. 
75. Snyder-Keller, A.; McLear, J.A.; Hathorn, T.; Messer, A. Early or late-stage anti-N-terminal huntingtin intrabody gene therapy reduces pathological features in B6.HDR6/1 mice. J. Neuropathol. Exp. Neurol. 2010, 69, 1078-1085.

76. Wang, C.E.; Zhou, H.; McGuire, J.R.; Cerullo, V.; Lee, B.; Li, S.H.; Li, X.J. Suppression of neuropil aggregates and neurological symptoms by an intracellular antibody implicates the cytoplasmic toxicity of mutant huntingtin. J. Cell Biol. 2008, 181, 803-816.

77. Zdobnova, T.A.; Stremovskiy, O.A.; Lebedenko, E.N.; Deyev, S.M. Self-assembling complexes of quantum dots and scFv antibodies for cancer cell targeting and imaging. PLoS One 2012, 7, e48248.

78. Xu, W.; Liu, L.; Brown, N.J.; Christian, S.; Hornby, D. Quantum dot-conjugated anti-GRP78 scFv inhibits cancer growth in mice. Molecules 2012, 17, 796-808.

79. Lee, A.S. GRP78 induction in cancer: Therapeutic and prognostic implications. Cancer Res. 2007, 67, 3496-3499.

80. Vigor, K.L.; Kyrtatos, P.G.; Minogue, S.; Al-Jamal, K.T.; Kogelberg, H.; Tolner, B.; Kostarelos, K.; Begent, R.H.; Pankhurst, Q.A.; Lythgoe, M.F.; et al. Nanoparticles functionalized with recombinant single chain $\mathrm{Fv}$ antibody fragments $(\mathrm{scFv})$ for the magnetic resonance imaging of cancer cells. Biomaterials 2010,31, 1307-1315.

81. Olafsen, T.; Wu, A.M. Antibody vectors for imaging. Semin. Nucl. Med. 2010, 40, 167-181.

82. Kumar, P.; Ban, H.S.; Kim, S.S.; Wu, H.; Pearson, T.; Greiner, D.L.; Laouar, A.; Yao, J.; Haridas, V.; Habiro, K.; et al. T cell-specific siRNA delivery suppresses HIV-1 infection in humanized mice. Cell 2008, 134, 577-586.

83. Pasche, N.; Wulhfard, S.; Pretto, F.; Carugati, E.; Neri, D. The antibody-based delivery of interleukin-12 to the tumor neovasculature eradicates murine models of cancer in combination with paclitaxel. Clin. Cancer Res. 2012, 18, 4092-4103.

84. Choi, S.; Lee, J.; Kumar, P.; Lee, K.Y.; Lee, S.K. Single chain variable fragment CD7 antibody conjugated PLGA/HDAC inhibitor immuno-nanoparticles: Developing human $\mathrm{T}$ cell-specific nano-technology for delivery of therapeutic drugs targeting latent HIV. J. Control Release 2011, 152 (Suppl 1), e9-e10.

(C) 2013 by the authors; licensee MDPI, Basel, Switzerland. This article is an open access article distributed under the terms and conditions of the Creative Commons Attribution license (http://creativecommons.org/licenses/by/3.0/). 